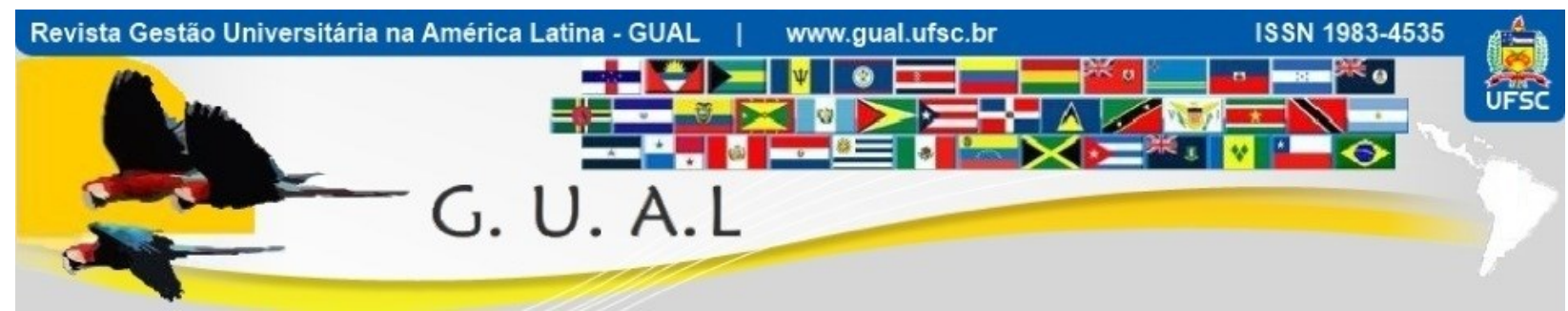

DOI: http://dx.doi.org/10.5007/1983-4535.2020v13n2p252

\title{
COMPETITIVIDADE E ESTRATÉGIA: NOVOS DESAFIOS PARA COORDENADORES DE CURSOS DE IES PRIVADAS NO BRASIL
}

\section{COMPETITIVENESS AND STRATEGY: NEW CHALLENGES FOR PRIVATE HEI COORDINATORS IN BRAZIL}

Patrícia Guimarães Rocha Saboya, Mestre https://orcid.org/0000-0002-0333-4773 patricia.saboya@hotmail.com Universidade da Amazônia | Curso de Graduação em Administração Belém | Pará | Brasil

Fernando Antônio Colares Palácios, Doutor https://orcid.org/0000-0002-5473-9973 fac.palacios@gmail.com Universidade da Amazônia | Programa de Pós-Graduação em Administração Belém | Pará | Brasil

Márcia Athayde Moreira, Doutora http://orcid.org/0000-0003-1859-6394 athayde.marcia@gmail.com

Universidade da Amazônia | Programa de Pós-Graduação em Administração Belém | Pará | Brasil

Naiara Silva Ferreira, Mestre https://orcid.org/0000-0002-3884-022X ferreira.s.naiara@gmail.com

Universidade Federal Rural da Amazônia | Programa de Pós-Graduação em Administração Belém | Pará | Brasil

Recebido em 04/outubro/2019

Aprovado em 13/março/2020

Publicado em 01/maio/2020

Sistema de Avaliação: Double Blind Review

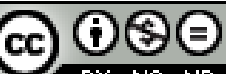

Esta obra está sob uma Licença Creative Commons Atribuição-Uso. 


\title{
RESUMO
}

O cenário do ambiente organizacional das Instituições de Ensino Superior privadas (IESP) no Brasil vêm se alterando com a formação de grandes grupos educacionais, por meio de fusões e incorporações e do desenho de um novo contexto da educação superior, diante de um ambiente de alta competição, pautado pela busca de vantagens competitivas e pela diferenciação. Nesse contexto, o objetivo dessa pesquisa foi o de analisar as competências utilizadas pelos coordenadores de curso para responderem às novas demandas estratégicas em uma IES privada que sofreu um processo de aquisição, passando a fazer parte de um grande grupo econômico da área educacional. Quanto à metodologia, trata-se de uma investigação qualitativa, exploratória, de amostra não-probabilística. Os resultados indicaram que o papel dos coordenadores de cursos vem sofrendo mudanças, sendo que alguns desses profissionais que já possuem experiência em gestão, adaptam-se mais facilmente; enquanto outros, sem experiência gerencial, através do sensemaking atribuem novo sentido às tarefas para serem capazes de desempenhar as funções. Concluiu-se que o cenário de alta competitividade das IESP tem impactado na atuação dos coordenadores, diminuindo a sua atuação acadêmica e o uso de competências para o gerenciamento do curso como uma unidade de negócios.

Palavras-chave: Ensino Superior Privado. Estratégia. Competências. Coordenação de Cursos. Sensemaking.

\begin{abstract}
The scenario of the organizational environment of private Higher Education Institutions in Brazil has been changing with the formation of large educational groups, through mergers and incorporations and the design of a new context of higher education, facing a high environment. competition, based on the pursuit of competitive advantages and differentiation. In this context, the objective of this research was to analyze the competences used by the course coordinators to respond to the new strategic demands in a private HEI that underwent an acquisition process, becoming part of a large economic group in the educational area. As for the methodology, it is a qualitative, exploratory investigation of a non-probabilistic sample. The results indicated that the role of the course coordinators has been changing, and some of these professionals who already have management experience adapt more easily; while others with no managerial experience through sensemaking assign new meaning to tasks to be able to perform their duties. It was concluded that the scenario of high competitiveness of the IESP has impacted the coordinators performance, reducing their academic performance and the use of competences to manage the course as a business unit.
\end{abstract}

Keywords: Private Higher Education. Strategy. Skills. Course Coordination. Sensemaking 


\section{INTRODUÇÃO}

As IES privadas (IESP) durante décadas mimetizaram as universidades públicas em sua estrutura e forma de gestão (REIS, 2016). Isso ocorria com a finalidade de conquistar legitimidade social. Na virada do século, de acordo com Sampaio (2000), desenvolveram novas formas organizacionais e passaram a elaborar modelos próprios de gestão que traduzem a preocupação com a sobrevivência e sustentabilidade empresarial. Entre as razões para essa mudança, é possível identificar uma de viés institucional: a nova regulação do setor a partir da década de 1990, que permitiu a aferição de lucro (ARAUJO, et al, 2018).

Essas alterações promoveram uma separação mais nítida entre o público e o privado no ensino superior (REIS, 2016), sendo ampliada ainda mais quando começaram a ocorrer as diversas fusões e incorporações que constituíram grandes grupos educacionais, transformando de forma radical o contexto da educação superior brasileira (ENDERS, 2015). Uma das consequências dessa transformação foi o acirramento da competitividade, passando as IES a adotarem modelos de gestão semelhantes às organizações empresariais na consecução de seus objetivos, abraçando a gestão estratégica (YANG, 2003).

Isso é possível comprovar por meio de um exemplo prático. A média gerência das IES é constituída pelos coordenadores de cursos de graduação. Antes das alterações, suas credenciais eram predominantemente acadêmicas, como, ser referência entre seus pares docentes, devido ao seu notável saber no campo de atuação e experiência comprovada. Nas IES privadas das grandes corporações são substituídos pela figura de gestores de unidades de negócios (PEREIRA et al, 2018), cujas funções requerem outras credenciais.

Essa nova liderança gestora é voltada para a parte administrativa da instituição, entendida como aquela relacionada aos aspectos estratégicos e regulatórios (KOK; MCDONALD, 2017), preocupada com a satisfação dos diversos stakeholders envolvidos: professores, alunos, acionistas, mercado, órgãos reguladores e sociedade; e não mais somente, com a parte acadêmica dos cursos (FONSECA e FONSECA, 2016). Esses cursos passam a ser entendidos como unidades de negócios (UN) que têm de apresentar resultados operacionais alinhados aos objetivos organizacionais, o que impacta definitivamente na atuação dos coordenadores de cursos (FONSECA e FONSECA, 2016).

Para atuar como gestores de UN, novas competências ao cargo são exigidas, implicando na mudança do perfil profissional dos coordenadores de curso buscam resolver os problemas e desafios cotidianos próprios das IESP, e abarcam, por exemplo: manter o 
negócio, captar e reter alunos para o curso, obter o apoio e a parceria dos professores para lidar com o ambiente concorrencial posto para o setor educacional privado na atualidade (ZAMBERLAN et al., 2010; MARCON, 2011; MEYER JR., 2014; FONSECA e FONSECA, 2016).

Desta forma, diante do contexto apresentado, o objetivo do estudo é o de identificar as competências necessárias e utilizadas pelos coordenadores de curso no cumprimento às diretrizes estratégicas de uma IESP, submersa no contexto competitivo próprio do setor na atualidade.

A metodologia aplicada envolveu pesquisa qualitativa e interpretativa de cunho exploratório, baseando-se em recursos bibliográficos e documentais que trazem em conjunto, artigos acadêmicos, trabalhos stricto sensu e documentos de múltiplas fontes, bem como foram realizadas entrevistas com os coordenadores de cursos da IES investigada. Para interpretação dos dados foi realizada a técnica de análise de conteúdo.

A abordagem teórica deriva de uma revisão da literatura sobre a competitividade e a estratégia na gestão de IES privadas, e as competências gerenciais do coordenador de curso no processo estratégico de sensemaking.

\section{A COMPETITIVIDADE E A ESTRATÉGIA NA GESTÃO DE IES PRIVADAS}

A competição estabelecida no novo contexto ambiental de grande imprevisibilidade em que se inserem as IES privadas no Brasil é objeto de estudos por meio da lógica estratégica. A estratégia e a gestão estratégica são apreciadas no contexto educacional desde a década de 1980, por meio de estudos como os de Baldridge (1983). No entanto, é somente a partir dos anos de 1990, que se estabelece a importância do planejamento estratégico neste tipo de organização, segundo Birnbaum (2000) corroborado por Meyer Jr. (2014) que entendem que o desenvolvimento de estratégias se volta para a sustentabilidade de seus negócios. Essa sustentabilidade é entendida pela busca do resultado financeiro da organização, seguindo a lógica do mercado competitivo (ENDERS, 2015).

A partir dessa nova abordagem estratégica, segundo Zanetin (2006), as IESP passam a apresentar práticas sociais, formas e estruturas semelhantes às empresas prestadoras de serviço, alterando a sua atuação original, quando se moldavam pelo modelo acadêmico e administrativo das universidades públicas. 
Naturalmente, as mudanças no formato de gestão das IESP exigiram dos seus coordenadores de curso uma nova gama de competências gerenciais distintas, antes não exigidas para a função (CEZARINO e CORRÊA, 2015).

\subsection{COMPETENNCIAS GERENCIAIS DO COORDENADOR DE CURSO}

A competência gerencial está associada com o desempenho efetivo do gestor (BOYATZIS, 1982). Nos estudos iniciais, o conceito de competência se solidificou em torno de três elementos-chave, propostos por Durand (1998): conhecimentos, habilidades e atitudes, interdependentes e necessários à consecução de determinado propósito. Nessa linha, autores conceituaram e complementaram o entendimento acerca da competência gerencial, tais como Potgieter et al. (2011), que a analisa como a capacidade de mobilizar recursos cognitivos para enfrentar e solucionar problemas de gestão.

Para Fleury e Fleury (2001) e Ruas (2002) as competências gerenciais se relacionam à agregação de valor econômico para a organização e também ao valor social que fornece ao indivíduo, estando associadas com a capacidade de mobilizar, integrar e transferir recursos para a geração de valor. Assim, competências gerenciais podem ser entendidas como um conjunto de conhecimentos, atitudes, habilidades que o indivíduo precisa, para obter eficácia nas suas ações, em uma prática responsável que se evidencia por meio de ações capazes de adicionar valor econômico às organizações e valor social ao indivíduo (FLEURY e FLEURY, 2001; CEZARINO e CORRÊA, 2015).

No campo de estudos sobre desempenho das IES, destaca-se Potgieter et al. (2011), que classificam o papel desempenhado pelos coordenadores de curso em quatro categorias de competências: acadêmica, administrativa, gestão e liderança.

A categoria de competências acadêmicas inclui: ministrar aulas, ser pesquisador, lidar com assuntos da faculdade, lidar com o staff acadêmico, representar oficialmente o departamento, realizar avaliações, ser facilitador, desenvolver o staff acadêmico e as programações do curso. A categoria de competências administrativas define-se como uma qualidade que o indivíduo traz para a posição, ser administrador de exames e admissões, testes e práticas (POTGIETER et al.,2011).

$\mathrm{Na}$ categoria de gestão ou gerencial, destacam-se as habilidades em conhecer finanças, gerenciar projetos, advogar pelas IES, fazer política, ser agente de mudanças e solucionador de problemas, saber lidar com conflitos, coordenar, delegar, saber lidar com problemas de 
disciplina, ser o officer encarregado, ser planejador, fazer o controle de qualidade, ser gerente de performance, gerenciador do tempo, gestor de relacionamento, recrutamento e seleção, gerir a diversidade e os riscos. A quarta e última categoria proposta por Potgieter et al. (2011) é a categoria de competências de liderança, traduzida pela capacidade de ser motivador, influenciar o grupo para a consecução dos objetivos e aconselhar e assumir riscos.

Nesse contexto, Fiorilo et al., 2015 discutem a importância da educação a distância para a educação superior na visão dos coordenadores a partir da perspectiva das competências desenvolvidas. E os resultados destacam quatro principais competências organizacionais desenvolvidas na instituição, que possibilitaram a aprovação do curso pelo MEC, a saber: gestão de avaliação de curso; gestão estratégica e de políticas para a Ead; gestão de recursos humanos e das equipes multidisciplinares; e gestão e planejamento da infraestrutura física e tecnológica.

Por sua vez, o Ministério da Educação (MEC), no Manual Geral de Avaliação das Condições de Ensino (MEC, 2002), discorre sobre as funções do coordenador de curso no processo avaliativo das IES, nos conceitos de sua atuação na coordenação, bem como, na participação nos órgãos colegiados das instituições de ensino superior e do curso; na ajuda didático-pedagógica aos docentes; descreve a relevância da titulação; do conhecimento e da experiência profissional na área acadêmica e na área administrativa; e dá atenção à administração e à condução do curso (FARINELLI e MELLO, 2009), além de elencar a sua participação nos resultados do curso que representa, como uma unidade de negócios da IES. Do coordenador de curso, portanto, de acordo com Farinelli e Mello (2009), são exigidas competências gerenciais que se transformem em resultados efetivos para o curso, além da agregação de valor econômico à IES.

Verifica-se, então, certo entendimento entre a percepção acadêmica proposta por Potgieter et al. (2011) e pela proposta do MEC (2002) para a atuação do coordenador de curso, em um contexto no qual a competência de gestão destaca-se cada vez mais em detrimento das demais, provocando mudança no paradigma da atuação do coordenador.

Cabe ressaltar, ainda, o entendimento de Sveiby (1992), centrado não no conteúdo das competências, mas como são desenvolvidas. $\mathrm{O}$ autor separa as competências gerenciais em cinco elementos: o conhecimento explícito, que possui embasamento na educação formal e na prática profissional; a habilidade, que é o treinamento e a prática profissionais; a experiência, que ocorre de maneira reflexiva; as de julgamento de valor, que é a percepção das situações; e 
a de rede social, ou seja, a de relacionamento com outros agentes, conforme apresentado na Figura 1.

$\mathrm{Na}$ análise de Sveiby (1992) distribuída nos cinco elementos: o que tange ao conhecimento explícito, é balizado na educação formal recebida pelo sujeito; já a habilidade, requer um treinamento e uma prática profissional; enquanto que a experiência ocorre de forma reflexiva, ou seja, em situações que causaram no ator uma reflexão; as de julgamento de valor baseiam-se nas percepções sobre situações; e a de rede social, no estabelecimento de relacionamento com outros atores.

Figura 01 Competências Gerenciais

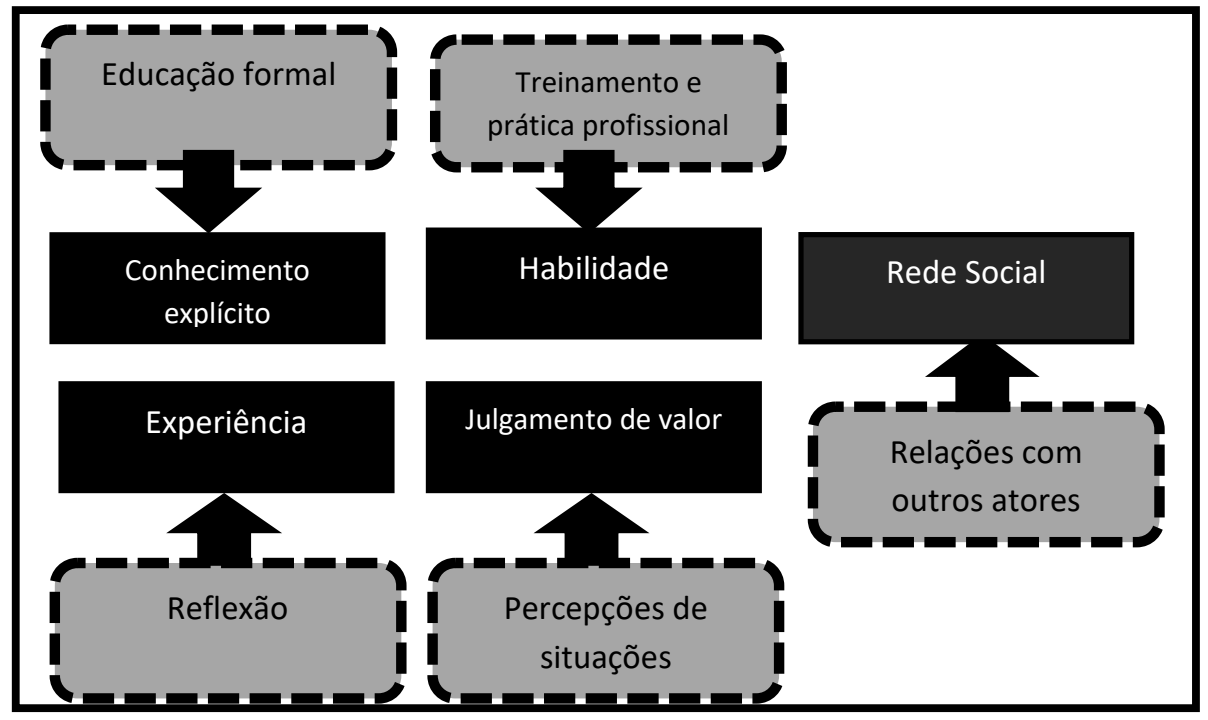

Fonte: Adaptação própria a partir de Sveiby (1992).

Verifica-se, portanto, que no julgamento de valor, o indivíduo atribui um sentido, isto é, percebe uma relação entre o sensemaking (fazer sentido) e a prática, podendo-se extrair que o fenômeno acontece no cotidiano do coordenador de curso. Este observa o processo no qual ainda lhe falta certa experiência, interpretando seus significados e compreendendo o mundo que o envolve, conferindo-lhes sentidos lógicos, sustentados pelo uso de seus esquemas mentais interiores (WEICK, 1995).

Essa junção de elementos da atuação do coordenador e a ênfase cada vez maior na competência de gestão provocam o surgimento de uma nova relação na vida profissional do indivíduo marcada pelo processo do fazer sentido (sensemaking) das práticas da atuação do coordenador de curso, onde o coordenador observa o processo. 


\subsection{O PROCESSO ESTRATÉGICO DO SENSEMAKING}

O sensemaking é um processo que ocorre por meio do uso de observações e experiências do indivíduo, que passa à sua realidade e os utiliza para nortear os seus comportamentos e atividades nos processos do cargo. $\mathrm{O}$ coordenador vê sentido na forma de se relacionar com os atores, por exemplo: na relação com os alunos e recomenda que o entendimento humano sobre os significados de algo é confirmado por meio da fala, e também pelo fazer, conforme atestam Reckwitz (2002) e Schatzki (2001).

O sensemaking é um conjunto de fazeres e dizeres interligados que contribuem para a compreensão da prática social, quando é necessário que o falar (sayings) e o fazer (doings) caminhem juntos. Essa ligação compreende: regras (leis, regras práticas, estatutos, padronização implícitas de comportamento); estruturas teleoafetivas (é um misto de ações orientadas para objetivos e relevância sobre as afetividades, através de valores, emoções, crenças, expectativas), e entendimentos (RECKWITZ, 2002).

O sensemaking promove a reconstrução de sentido de forma retrospectiva (sensemaking retrospective), embasada em uma experiência vivida e significativa para o agente (meaningful lived experience), onde os agentes têm ciência do que estão praticando após já o terem feito (WEICK, 1976). É a reconstrução de sentido ou de significados realizada pelas partes envolvidas e ocorre amparado pela prática, em três ocasiões: scanning (coleta de dados); interpretation (interpretando e manifestando significados aos dados coletados); e learning (aprendizado/medida tomada).

Waterman (1990) sustenta que sensemaking é o processo de dar sentido para algo desconhecido, enquanto que para Vieira e Fonseca (2009), é o que é, de que maneira e o motivo pelo qual é construído. A abordagem, então, avigora que são as maneiras de os agentes perceberem, compreenderem e sentirem o processo, além de se permitirem entender de que forma usam a informação e os recursos nele contidos (DERVIN, 1998; GIOIA; MEHRA, 1996; WEICK, 1995). O fazer sentido é importante para o sujeito ressignificar a atividade, a rotina e as tarefas envolvidas no seu agir.

Dessa forma, a compreensão acerca do fazer e do falar, de dar sentido à ação torna-se mais importante em uma IES que passa por uma alteração na alta gerência devido a um processo de incorporação. A partir da mudança de Mantenedora mudam os atributos e as competências que os coordenadores de cursos acadêmicos (pertencentes a uma gestão intermediária) devem possuir para gerir as unidades de negócios, em consonância com as 
novas estratégias organizacionais, imputando-lhes um novo sentido e naturalmente uma nova interpretação da utilização de suas competências para a gestão da coordenação do curso.

\section{METODOLOGIA}

A metodologia aplicada foi de cunho qualitativo e exploratório, abordando os argumentos apresentados no referencial teórico e entrelaçando com as perspectivas dos dados coletados sobre o problema. Este tipo de pesquisa se concentra na compreensão de fenômenos de forma mais abrangente e busca mostrar analiticamente os significados, práticas, motivações,comportamentos e revelar como estes permitem interpretar relações entre variáveis e fenômenos, porém de forma subjetiva, o que requer interpretação cuidadosa e rigorosa (FARIAS FILHO, 2018, p.55).

A amostra dos sujeitos ocorreu pelo tipo não-probabilística - selecionada por tipicidade - por meio da seleção de elementos representativos da população (VERGARA, 2014, p.20). Assim, resultou na eleição dos cursos acadêmicos de: Administração, Engenharia Civil, Direito e Psicologia, por cada um destes possuir o maior número de alunos, representando, portanto, cada um, uma diretoria acadêmica diferente: Administração, representando o Centro de Ciências Humanas e Sociais (CCHS); Engenharia Civil, o Centro de Ciências Exatas e Tecnológicas (CCET); Direito, o Instituto de Ciências Jurídicas (ICJ); e Psicologia, o Centro de Ciências Biológicas e da Saúde (CCBS). Foram realizadas no total oito entrevistas, com duração média de 50 minutos: uma com o coordenador atual do curso; e outra com o antigo coordenador, em um espaço de 35 dias, correspondente aos meses de agosto e setembro de 2016.

Para os oito coordenadores escolhidos para participar da pesquisa, foi elaborado um roteiro de entrevistas, o qual contém três perguntas que buscam capturar as competências e a percepção do coordenador acerca de suas atividades, de acordo com a Figura 2.

Esse roteiro foi submetido à validação junto a dois pesquisadores da área, bem como foi efetivado o pré-teste com dois coordenadores de cursos de uma outra IES privada.

O método para análise e organização dos dados coletados foi a Análise de Conteúdo (BARDIN, 2006), quando utilizada em pesquisas qualitativas representam uma derivação da comunicação, ajudando na interpretação, compreensão e descrição do conteúdo das mensagens procedidas (FARIAS FILHO; ARRUDA FILHO, 2013). 
Figura 2 Roteiro de entrevistas - (parte1)

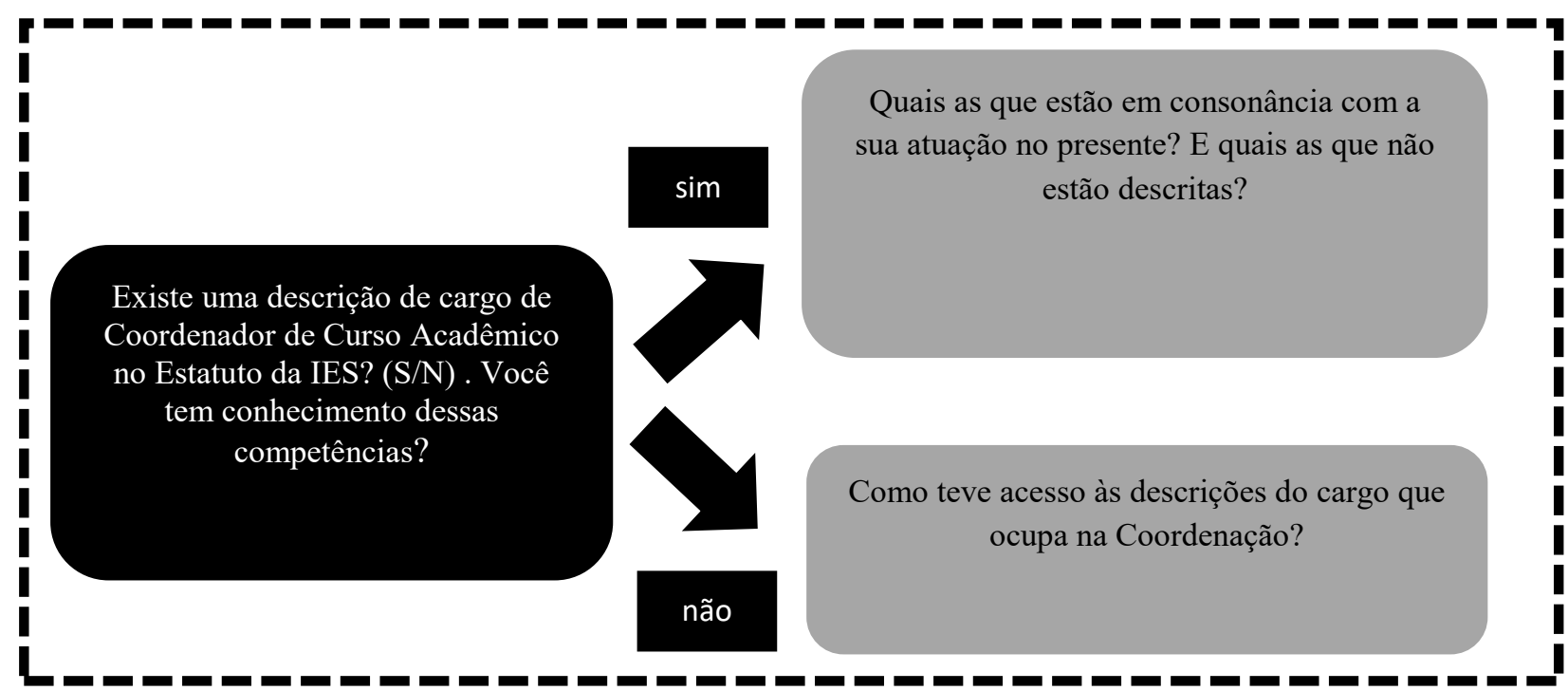

Entrevistas (parte 2)

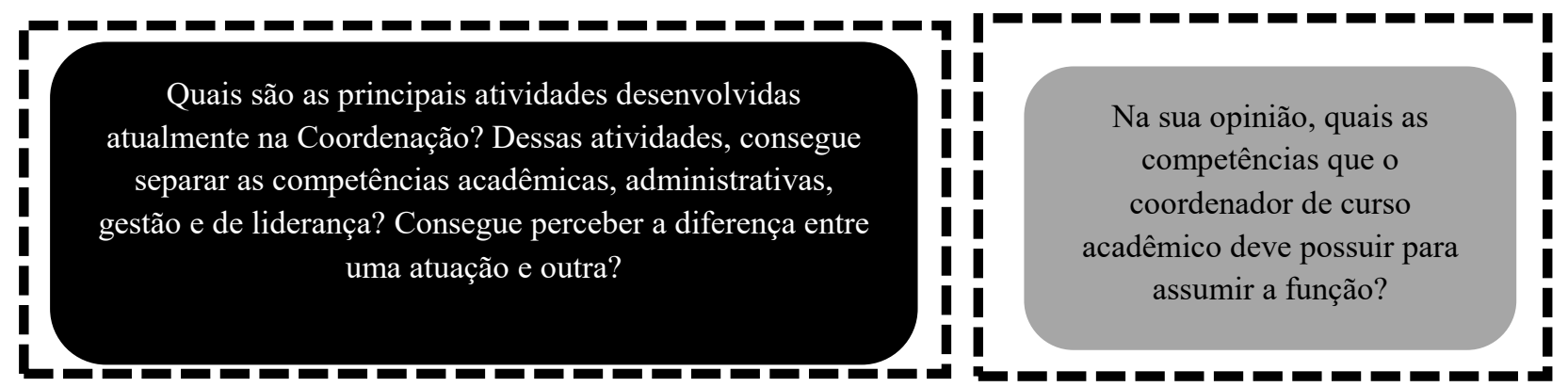

Fonte: Elaborada pelos autores (2019).

A Análise de Conteúdo (AC) foi útil na definição das subcategorias de exame no tratamento dos dados, as quais foram determinadas a posteriori, isto é, após a análise das falas dos analisados, procedendo nas seguintes subdivisões, de acordo com a classificação de representação de categorias da pesquisa de Potgieter et al. (2011), segundo o quadro 01.

Quadro 01 Categorias de competências: funções e representações

\begin{tabular}{|c|c|c|}
\hline Funç̃es & Representacões & Subcategorias/ subdivisões \\
\hline \multirow{4}{*}{ ACADÊMICA } & Ministrar aulas; ser pesquisador; saber & \\
& lidar com assuntos da faculdade e com o & \\
& staff acadêmico; representar oficialmente o & 1- Ministrar aulas; 2-Representação \\
& departamento (coordenação do curso); & do curso; 3- Controle dos egressos; 4- \\
& realizar avaliações; ser um facilitador; & Turmas ENADE \\
& desenvolver o staff acadêmico e as & \\
& programações do curso. & \\
\hline
\end{tabular}




\begin{tabular}{|c|c|c|}
\hline Funç̃es & $\underline{\text { Representações }}$ & Subcategorias/subdivisões \\
\hline DE GESTÃO & $\begin{array}{l}\text { Ter conhecimento de finanças; gerenciar } \\
\text { projetos; advogar pela IES; fazer política; } \\
\text { ser agente de mudanças e solucionador de } \\
\text { problemas; ter capacidade de lidar com } \\
\text { conflitos e problemas de disciplina; } \\
\text { coordenar; delegar; ter capacidade de ser o } \\
\text { officer encarregado; planejar; fazer o } \\
\text { controle de qualidade; ser gerente de } \\
\text { performance; ser gestor de recrutamento e } \\
\text { de seleção; gerir a diversidade e os riscos; } \\
\text { ser gestor de relacionamento. }\end{array}$ & $\begin{array}{l}\text { 1- Compreensão dos objetivos } \\
\text { estratégicos; 2- Experiência na função } \\
\text { de coordenador; 3- Treinamento para } \\
\text { a gestão; 4- Descrição do cargo de } \\
\text { coordenador; 5- Mudança do papel do } \\
\text { coordenador; 6- Desafios da função; } \\
\text { 7- Relacionamento com os } \\
\text { stakeholders; 8- Sensemaking. }\end{array}$ \\
\hline ADMINISTRATIVA & $\begin{array}{l}\text { Administrar exames e admissões, testes e } \\
\text { práticas. }\end{array}$ & Não verificada \\
\hline DE LIDERANÇA & $\begin{array}{l}\text { Ser motivador; influenciar o grupo para a } \\
\text { consecução de objetivos; e assumir riscos }\end{array}$ & $\begin{array}{c}\text { 1- Comunicação; 2- Estabelecimento } \\
\text { de Parcerias }\end{array}$ \\
\hline
\end{tabular}

Fonte: Adaptado de Potgieter et al. (2011).

Para identificar as competências utilizadas pelos coordenadores de curso no seu fazer profissional cotidiano da IES objeto desse estudo, utilizou-se a análise da pesquisa de Potgieter et al. (2011), sobre as competências gerenciais aplicadas a esses indivíduos para comparações com as descrições dos seus cargos no documento da IES.

\section{ANÁLISE DOS RESULTADOS}

A despeito das quatro representações das competências do coordenador de curso (Administrativa; Acadêmica; de Liderança; e de Gestão), tendo como base o objetivo geral da pesquisa, foi dado ênfase para a função de Gestão, na qual, dentre outras, foram categorizadas subcategorias representativas: Compreensão dos objetivos estratégicos; e Sensemaking.

Dentre essas categorias foram objeto de análise as competências utilizadas pelos coordenadores de curso para responderem às novas demandas estratégicas no espectro da sua compreensão face aos objetivos estratégicos da instituição e também o fazer sentido na sua atuação como gestor de unidade (Sensemaking).

\subsection{COMPREENSÃO DOS OBJETIVOS ESTRATÉGICOS}

Compreender os objetivos estratégicos da IES e conhecer sobre as mudanças que envolvem o ambiente competitivo em que se inserem tais instituições é essencial para o exercício da função de coordenador de um curso acadêmico no atual contexto dessas organizações educacionais privadas, com a finalidade de obtenção de meios de trabalhar através das metas corporativas e o alcance dos objetivos organizacionais (HAMLIN; PATEL, 
2017). Desta forma, é necessário que os coordenadores possuam a visão do todo, como uma competência para a sua função junto à coordenação, o que se observa na entrevista do coordenador E2:

[...] eu trabalho com a gestão universitária já vai fazer 24 anos que eu trabalho com isso! E eu digo que você precisa buscar entender aonde a tua empresa quer chegar. E esse aonde quer chegar é muito rápido que ela muda de ideia, né? Ela tem um foco! (...)você tem que entender que tem o pensamento dela de crescimento e que você tem uma meta que hoje você trabalha, é bem gestão por objetivos, mesmo! Visão de Peter Drucker, trabalhando por meta, você tem as metas pra atingir, e que, muitas das vezes, quando você faz análise do cenário, você visualiza uma meta para cada curso, pra cada percepção de curso, mas essa meta, quando ela foi desenhada, o cenário econômico-político, ele passa por flutuações, mas a tua meta não muda e tu continuas tendo que trabalhar dentro dessa perspectiva. Hoje eu digo, tu precisas conhecer muito bem a parte operacional que tu trabalhas, tá? Para que você possa se adequar! (Entrevistado E2).

$\mathrm{Na}$ fala do Entrevistado E4, observa-se que existe um entendimento acerca das estratégias voltadas ao atingimento dos objetivos da instituição. Quando questionado sobre as estratégias traçadas pela IES para o seu curso, ou seja, o "como" fazer, uma vez que é a IES Mantenedora que determina as estratégias (macro) corporativas, o mesmo responde que são debatidas as ideias nas reuniões com a alta gestão (diretoria) e compartilhadas as sugestões com os demais cursos:

O 'como', na verdade, é..., a gente costuma idealizar em reunião de centros. (...) Então, algumas ações a gente até compartilha pros outros cursos. (...) essas estratégias são debatidas com o diretor e com os outros coordenadores. (...) a gente tem o objetivo que é captação, por exemplo, captação no colégio $\mathrm{X}$, então, de acordo com o resultado das ações anteriores nós tiramos algumas conclusões e vemos em que caminho a gente deve seguir. Se deve, por exemplo, algumas ações que não tiveram resultados, nós vamos descartar, né? Alguns procedimentos, algumas coisas pra fazer e as que deram certo, as novas ideias vão ser discutidas em conjunto entre os coordenadores do centro. (...) trocar. (...) ouvir; compartilhar ideias e sugestões. Tanto do diretor, quanto dos outros coordenadores (Entrevistado E4).

O Entrevistado E2 menciona que existem as estratégias que são gerais para a IES e que abarcam todos os cursos acadêmicos; e também, aquelas que são direcionadas ao seu curso especificamente. Assim, o entrevistado compreende a relevância do entendimento do coordenador sobre essas diferenças, ou seja, das estratégias globais e das específicas:

[...] você vai ter que pensar que algumas estratégias tuas vão ser globais. Pra envolver todos os cursos. E você vai ter as estratégias direcionadas somente 
pro teu curso. (...) então, você tem que ter uma visão da rotina, né? $\mathrm{Da}$, e uma visão estratégica para que o aluno e o professor entendem que são dois cursos. Hoje isso pra nós é bem, é bem visível, até pra que no momento operacional, quando você cria os horários, tá? Mas se você for pra um outro grupo ele ainda não tem essa visão. Ele coloca aluno de Administração, Contábeis, Comunicação, tudo junto, nas disciplinas, mas ele não percebe que ele precisa de uma estratégia diferenciada (Entrevistado E2).

\subsection{SENSEMAKING}

O sensemaking (fazer sentido) surge apenas na fala de um dos entrevistados Entrevistado E8 - embora esteja presente no pensar daquele coordenador que não possui formação acadêmica na área de gestão ou experiências em cargos afins.

$\mathrm{Na}$ fala do Entrevistado E8, entende-se que o seu agir - todas as ações que comete no cargo de gestão - é explicado pelos sentidos que confere ao relacionamento com o outro, seja ele: aluno, diretor, professor ou pais de alunos. $\mathrm{O}$ agente acredita que o seu cargo pode fazer diferença quando empreende uma forma reflexiva sobre os motivos da ação. O Entrevistado E8, ao desempenhar a função de gestor pela primeira vez busca dar sentido às ações demandadas pela estratégia corporativa da IES, que lhe são questionadas quanto ao seu sentido ou o benefício que ocasionarão.

Verifica-se na análise de sua fala, que o sensemaking ocorre através da comunicação efetiva, da obtenção da compreensão, do diálogo estabelecido e do relacionamento constituído através de um evento, como: ligar para o aluno para evitar sua evasão. Este evento ligação é uma diretriz corporativa, no entanto, para o gestor ocorre uma reflexão prévia de promover um sentido da ação:

[...] a partir do momento que eu começo a ligar (...) a gente começou a constatar que muitas pessoas interrompiam o curso por questões financeiras, elas sempre são uma constante, mas, às vezes, elas são sintomas ou são expressões de dilemas pessoais, de dificuldades pessoais. Por exemplo, têm alunos que:'ah, tô com uma dificuldade financeira!' (...) 'aqui quem fala é o professor' (...), 'eu sei quem você é, sabe? Eu te conheço. O que aconteceu? (...) tu não queres vir aqui, conversar melhor comigo? Porque se tu fores trancar mesmo, tu tens que vir aqui conosco (Entrevistado E8).

Somente faz sentido executar rotinas organizacionais se o sujeito conseguir estabelecer uma relação com o aluno. Isso ocorre não somente pela falta de conhecimento de gestão ou de uma formação acadêmica que não abarca a gestão, mas da habilidade de perceber no outro, através da comunicação, do diálogo e do relacionamento, o fator humano, que surge autonomamente, desagregado da formação acadêmica ou dos conhecimentos acumulados. 
Isso é humano! Você, no processo de tornar-se humano, do humanizar-se! Se eu tivesse preocupado apenas como, (...) se eu tivesse ligando apenas como uma pessoa que tem uma meta de, é, é... aquelas coisas de serviço, que a gente sabe que aquela pessoa tem 200 pessoas pra ligar, ela liga pra você, se você diz não, ela já passa pro próximo. Sabe? (...) mas eu, ainda assim, poderia obstruir esse percurso, se eu tivesse só ligado pra ela, e ela: - Ah, professor, eu acho que eu tô pensando em interromper. Se a minha cabeça tivesse só na (...) captação e evasão, como bases, como sustentáculo absoluto e não percebesse que essas duas estão, de certa forma, apoiadas no humano, ou nesse processo de humanizar, ou melhor, na relação das pessoas, o...eu teria desligado logo (...) Mas, ao mesmo tempo, se eu me dou conta, se eu consigo ouvi-la, realmente, ouvi-la (...)! (Entrevistado E8).

A competência é o saber agir de forma própria, diferente e individual, diante de fatos rotineiros ou esdrúxulos que acontecem no cotidiano do trabalho e que demanda que o agente possua conhecimentos, atitudes e habilidades, que podem surgir através do sensemaking. Uma prática reflexiva da ação. As atitudes devem fazer sentido ao interagente, cujo foco é a relação e o objetivo será alcançado em decorrência do relacionamento ora estabelecido.

[...] e eu tô, se eu ligo pras pessoas e tento ouvi-las e se essa escuta vai oportunizar uma evasão ou uma captação, isso é uma consequência. $\mathrm{O}$ meu objetivo central é a relação. Se essa relação resulta na sensação de que ela, infelizmente, vai trancar e ela tranca com lágrimas nos olhos, como eu já tive alunos aqui, que eu entreguei o papel autorizando o trancamento e a menina chora na minha frente porque não é o que ela queria, mas decisões familiares, decisões maiores, condições, as quais, ela não tem como governar, se impõe sobre ela, e na vida, às vezes, situações assim, implicam a gente a baixar a cabeça e aguardar, aguardar que o vento passe, que os tempos melhorem (...) Então, isso é o contato humano! Isso é a relação! (Entrevistado E8).

O sensemaking fornece um sentido através da visão de mundo do agente e da forma como este constroi o processo.

E aí essa pessoa veio. (...) no processo, ela começou a se dar conta, ela já tava no oitavo semestre, finalizando o curso, e aí, durante a conversa ela começa a expressar que... ela, por exemplo, não tinha feito um bom sétimo semestre (...) começou, também, a perceber que, dentro daquele contexto familiar que tava ruindo, e as questões financeiras afetando, de maneira demasiada isso, essa aluna decidiu tomar a decisão de interromper o curso acreditando que isso salvaria aquela situação durante o nosso diálogo ela foise dando conta desse processo fantasioso dela, assim, que, tá certo que a situação financeira tinha mudado na família, mas depois, durante a conversa ela falou assim, professor, na verdade a minha mãe nem quer que eu interrompa. A gente até tem condições muito tranquilas de pagar, é porque pra mim é muito difícil ver o que que está acontecendo e ficar só sendo mais alguém que não está contribuindo (Entrevistado E8). 
Também, o sensemaking dá sentido ao desconhecido. Para o entrevistado, o fazer sentido tem relação estreita com esse desconhecido. A competência individual não se limita apenas aos conhecimentos do agente, mas ao seu próprio saber-fazer, realizado diante de situações inusitadas que ocorrem na rotina do trabalho. Esse saber-fazer é particular ao sujeito, o que se constata que existe semelhança entre o sensemaking e o exercício na coordenação de curso, como na fala do Entrevistado E8:

Então, o grande dilema que nós tínhamos era justamente esse: será que a gente consegue, do lugar que a gente ocupa é... assumir os dispositivos que a gente dispõe, as ferramentas que a gente possui e favorecer, não apenas, as metas, as exigências institucionalizadas, institucionais? Ou a gente consegue ofertar espaços pra construção de relacionamentos humanos? Que é impossível você separar essa aptidão nossa, aptidão humana de racionalizar as relações, os papeis, ritualizar as experiências, não significa. Ritualizar as experiências não significa se contrapor ao favorecimento do relacionamento humano (Entrevistado E8).

O desempenho do Entrevistado E8 sofre influência do fator relacional e baliza a sua ação como gestor, ao verificar oportunidades de construir relações com os alunos através das rotinas institucionais, como a captação de alunos e o controle da evasão.

$\mathrm{Na}$ verdade, a questão de proatividade, a pessoa que tá à frente de uma gestão, ela tem que ser proativa, então, as coisas acontecem muito rápido os processos - e de acordo com o mercado, as demandas vão acontecendo muito rapidamente! Nós somos um grupo muito grande, então, nós temos muitas ferramentas de controle da gestão. Então precisa ser uma pessoa que tenha domínio, a questão da liderança, então, se você não tiver a liderança em relação aos docentes e aos seus alunos você não consegue gerir o curso, porque você depende de todo esse ciclo, né? Tem a diretoria que lhe dá suporte, mas os docentes, é que tão em sala de aula que movimentam o teu trabalho. Então, se você não tiver liderança perante os docentes você não consegue trabalhar (Entrevistado E8).

Embora o coordenador efetue suas observações sobre os processos e rotinas organizacionais de maneira recente ou ainda em construção, este interpreta os seus sentidos e passa a entender esse universo da gestão que o envolve, atribuindo-lhes sentidos lógicos, escorados no uso de seus esquemas mentais interiores. O sensemaking é um veículo, através do qual, utiliza suas observações e experiências para construir a sua realidade e orientar as suas condutas nos processos de gestão, nos quais está submetido.

Vieira e Fonseca (2009) relatam que o sensemaking se baseia nas questões sobre “como?", "por quê?” e “do que” é construído o sentido. Esse enfoque avigora as maneiras de 
os agentes compreenderem e sentirem o processo e de que jeito utilizam a informação e os recursos (DERVIN, 1998; GIOIA e MEHRA, 1996; WEICK, 1995).

Então, quando eu venho pra cá, entro na instituição, a professora (Coordenadora, até então) me convida é... eu travava muito com ela essa discussão sobre no lugar que a gente ocupa, enquanto coordenador de uma instituição hoje, e sempre. Ela sempre foi privada. O que muda não é a instituição. O que muda é o cenário mundial; é o cenário nacional. As instituições se adequam. Umas conseguem; outras não conseguem. (...) Então o grande dilema que nós tínhamos era justamente esse, será que a gente consegue, do lugar que a gente ocupa é... assumir os dispositivos que a gente dispõe, as ferramentas que a gente possui e favorecer, não apenas, as metas, as exigências institucionalizadas, institucionais? Ou a gente consegue ofertar espaços pra construção de relacionamentos humanos? Esse questionamento, embora ele seja interessante, ele ainda tem um problema: ele coloca uma coisa em detrimento da outra. Eu acho que o grande ponto de autores como Paul Ricouer, e essa é uma percepção que eu tenho, é que uma coisa não e contraposta à outra (Entrevistado E8).

O coordenador, ao cumprir o que é instituído pela IES, como o realizar os telefonemas aos alunos para controle da evasão, o faz de um modo diferenciado ou próprio da sua competência individual porque atribui um sentido nessa ação, quando consegue estabelecer uma relação com o aluno abordado: exercita a escuta e acredita crê que isso é próprio da gestão.

Te dou um exemplo que... ao assumir a gestão, claro, ainda como adjunto, uma das minhas tarefas, na nossa organização de atividades (...) era vincular a questão das ligações pros (sic) alunos. (...) não se matriculou, o que está acontecendo? Se eu... de maneira fria, essa é uma experiência de ligar pras pessoas pra sondar se elas farão ou não a sua matrícula. Se ela não faz, o que está acontecendo? Uma questão de financeiro? E a gente tem setores que dão conta disso. (...)Assim, até alguns nossos professores, a princípio, interpretaram que, eu mesmo, cheguei uma hora e fiquei assim: é interessante a gente ficar ligando pras pessoas? Pra mim, isso era uma coisa muito estranha! Não conseguia conceber que, por ignorância e por preconceito, entendi isso como essa expressão dessa racionalidade (...) ela pode ser, sim, uma expressão que favoreça esse contato humano (Entrevistado E8).

\section{DISCUSSÃO DOS RESULTADOS E CONSIDERAÇÕES FINAIS}

Através das análises efetuadas a partir das entrevistas dos sujeitos, a pesquisa pôde verificar que os coordenadores admitem que os cursos são unidades de negócios e compreendem que existe a gestão estratégica e que o seu fazer profissional é balizado pelos objetivos corporativos, o que vai ao encontro da literatura que discorre sobre o novo cenário 
competitivo e suas práticas com vistas à sustentabilidade organizacional (ARAUJO, et al, 2018).

Apesar de o sensemaking surgir de forma clara apenas na fala de um dos oito entrevistados, de acordo com Weick (1995), constitui um caminho utilizado para a compreensão de que forma esses gestores conferem sentido através de sua visão de mundo e constroem as suas obrigações e utilizam as informações durante o processo da gerência.

No estudo constatou-se que, quando o coordenador não possui experiência na gestão ou quando não possui formação acadêmica em Administração, possui maior dificuldade acerca das rotinas dentro da função, ou seja, na compreensão dos instrumentos de gestão, das rotinas administrativas e da própria linguagem gerencial, até mesmo no que tange às práticas sistemáticas referentes às principais abrangências do curso, como o controle de evasão de alunos e a captação.

Assim, o dia a dia no exercício do cargo na coordenação é mais facilitado para àqueles sujeitos que já possuem certa experiência de gestão, comparados àqueles que, ou por não possuir formação acadêmica na área ou por não terem tido algum cargo em gestão, passando, portanto, a atribuir sentidos lógicos, baseados na sua visão de mundo para esse fazer diário e rotineiro.

Baseado na entrevista com o coordenador que traz o tema do sensemaking, verifica-se na bibliografia que a mesma já havia atestado esta ser uma importante categoria de estratégia, corroborado por Waterman (1990), quando afirma pertencer ao processo de dar sentido para algo ainda desconhecido, ou seja, o fato de concretizar determinadas rotinas no intuito de conseguir reter e captar alunos deve fazer algum sentido para o agente, ou por não compreender apenas como um cumprimento obrigatório pelo fator técnico-administrativo da tarefa.

Isso também é apurado quando surgem questionamentos acerca do significado que inflige ao evento de cumprimento de uma meta corporativa, mas ainda por fazer parte da trajetória acadêmica do aluno da importância desse seu agir individual e particular, quando, por exemplo, o entrevistado declara envolver-se com questões do aluno, tentando a sua escuta para estabelecer significados às práticas exigidas pela IES.

O fazer sentido possui essa inequívoca e estreita relação com o ignorado/ desconhecido, onde a função de coordenador acarreta uma competência individual, não restrita a conhecimentos teóricos apenas, alcançados pelo indivíduo, mas também não se 
encontra no ato de realizar a tarefa (ZARIFIAN, 2012). É um saber-fazer singular, individual e próprio, aplicado em várias situações na conjuntura do trabalho. São estruturas teleoafetivas (SCHATZKI, 2001) que guiam os praticantes: ora vinculado às emoções; ora aos valores, às crenças e aos significados.

Esse fazer sentido pode demarcar a criticidade das atividades de rotina efetuadas por esses agentes, colaborando para a aprendizagem das organizações e para a experiência nessas ações, o que, no lapso temporal, acumular-se-á, nas experiências vividas pelos coordenadores no exercício de suas funções, bem como para aqueles sujeitos sem conhecimento acerca de gestão, que, ao conjecturarem sobre o que lhes é exigido, poderão construir seus próprios sentidos (NUNES, 2010).

Os coordendores de cursos precisam de um arcabouço de competências para que conseguirem desempenhar com sucesso a sua função (CEZARINO; CORRÊA, 2015). Para tanto, é preciso que compreendam o quanto é importante a sua preparação o conhecimento acerca da gestão de uma unidade de negócios para que consigam fazer a transição de professor acadêmico para gestor de um curso.

Constata-se que os desafios que envolvem esses coordenadores orientam-se na competência de gestão, citada com todas as suas funções por Potgieter et al. (2011); mas de forma particular, aos docentes-coordenadores sem experiência ou conhecimento de gestão, através dos sentidos que conferem às práticas e rotinas da função.

Pode-se concluir, a partir das decorrências deste estudo que o papel dos coordenadores de cursos em IES privadas sofreu modificações, fazendo com que evoluíssem para que avocassem encargos, não somente acadêmicos, que são próprios da função, mas ainda, de gestão. E a esse papel acadêmico vem sendo imputadas reduções na sua finalidade, conferindo-se ênfase às questões gerenciais para a sobrevivência organizacional, por meio das atenções à captação e à retenção de alunos.

A maioria desses sujeitos está se adequando rapidamente ao novo contexto, entendendo-se que não manifestam um posicionamento crítico a respeito. Pôde-se perceber que dentre as razões do enfraquecimento do papel do coordenador de curso a um perfil administrativo-gerencial, está o fato de as instituições terem o aluno como um cliente.

Os coordenadores, participantes da média gerência da IES sob análise, e nos achados deste estudo, assumem uma postura que segue a lógica do mercado concorrencial do ensino superior privado da atualidade. Considera-se que a abrangência das competências gerenciais 
desses sujeitos para o exercício da função, não abarca somente a gestão da unidade de negócios (cursos acadêmicos), mas também, a qualidade acadêmica, a preocupação com a formação dos alunos e a empregabilidade dos seus egressos, por entender que a atividade precípua das IES é a profusão do conhecimento e a formação do aluno.

As explicações dos achados desta pesquisa devem ser limitadas à presente investigação, considerando que sua amostra foi executada em uma IES privada no norte do Brasil, o que pode não admitir generalizações para todas as instituições de ensino superior. Contudo, apesar dessas demarcações, os resultados assinalam para valiosas contribuições acerca da temática e do desenvolvimento do papel dos coordenadores de cursos acadêmicos no contexto de IES privadas no Brasil. Tais contribuições talvez possam servir de balizamento para futuros estudos.

\section{REFERÊNCIAS}

ARAÚJO, Christine Veloso Barbosa; SILVA, Viviane Nascimento; DURÃES, Sarah Jane. Processo de Bolonha e mudanças curriculares na educação superior. Educação e Pesquisa, v. 44, p. e174148-e174148, 2018.

BALDRIDGE, J. V. et. al. Organizational Characteristics of Colleges and Universities. In: J. V. Baldridge \& Del (editors). The Dynamics of Organizational Change in Education.Berkeley: McUtchan, 1983, p. 38-59.

BARDIN, L. Análise de conteúdo (L. de A. Rego \& A. Pinheiro, Trads.). Lisboa: Edições 70, 2006.

BRASIL. Ministério da Educação. Disponível em: $<$ http://portal.mec.gov.br/sesu/arquivos/pdf/Manual1.pdf $>$ Acesso em: 02/10/2017.

BIRNBAUM, Robert. Management fads in higher education: Where they come from, what they do, why they fail. San Francisco: Jossey-Bass, 2000.

BOYATZIS, R. E. The competence manager: A model for effective performance. New York: John Wiley \& Sons, 1982.

CEZARINO, Luciana Oranges; CORRÊA, Hamilton Luiz. Interdisciplinaridade no ensino em Administração: visão de especialistas e coordenadores de cursos de graduação. Administração: ensino e pesquisa, v. 16, n. 4, p. 751-784, 2015.

DERVIN, B. Sense-Making the ory and practice: An overview of user interests in knowledge seekingand use. Journal of Knowledge Management, v.2, n.2, Dec, p.36-46. 1998. 
DURAND, Thomas. FormsofIncompetence. In: Sanchez, R. Heene, A. TheoryDevelopment for Competence-Based Management, v. 6. Advances in Applied Business Stractegy, Lawrence Foster, series editor, Greenwich, CT: JAI Press, 1998.

ENDERS J. Higher Education Management. International Encyclopedia of the Social \& Behavioral Sciences: Second Edition, p. 845-849, 2015.

FARIAS FILHO, Milton C. Elaboração de Artigo para Publicação: Um Guia para as Ciências Sociais, Sociais Aplicadas e Humanidades. São Paulo. Serie Produção Científica Volume 1, Ed. Motres, 2018, 118 p.

FARINELLI, Clairna Andresa. MELO, Marlene Catarina de Oliveira Lopes. A Gerência Intermediária da IES: A Coordenação de Curso e o Coordenador como Gestor. In: IX COLÓQUIO INTERNACIONAL SOBRE GESTÃO UNIVERSITÁRIA NA AMÉRICA DO SUL. Florianópolis. Nov.2009.

FIORILLO, Aurélio; MACCARI, Emerson Antonio; MARTINS, Cibele Barsalini. A EaD no Brasil e a importancia de competencias subjacentes para o reconhecimento de cursos de acordo com a percepcao de coordenadores de curso. Administração: Ensino e Pesquisa, v. 16, n. 1, p. 141-178, 2015.

FLEURY, Maria Tereza L. FLEURY, Afonso. Construindo o Conceito de Competência. RAC, Edição Especial 2001: 183-196

FONSECA, Marília. FONSECA, Dirce M. A gestão acadêmica da pós-graduação lato sensu: o papel do coordenador para a qualidade dos cursos. Educ. Pesqui., São Paulo, v. 42, n.1, p. $151-164$, jan./ mar. 2016.

GIL, Antonio Carlos. Como elaborar Projetos de Pesquisa. São Paulo. Editora Atlas, 2002.

GIOIA, D. A. e MEHRA, A. Sensemaking in Organizations. Academy of Management Review, v.21, n.4, p.1226-1230. 1996.

HAMLIN, Robert G.; PATEL, Taran. Perceived managerial and leadership effectiveness within higher education in France, Studies in Higher Education, 42:2, 292-314 2017, DOI: $\underline{10.1080 / 03075079.2015 .1045480}$

MAINARDES, Emerson. FERREIRA, João. TONTINI, Gerson. Vantagens Competitivas em Instituições de Ensino Superior: proposta e teste de um modelo. In: IX COLÓQUIO INTERNACIONAL SOBRE GESTÃO UNIVERSITÁRIA NA AMÉRICA DO SUL. Florianópolis, 2009.

MARCON, Silvana R. A. Atribuições dos cargos de coordenação e subcoordenação de cursos de graduação. In: XI COLÓQUIO INTERNACIONAL SOBRE GESTÃO UNIVERSITÁRIA NA AMÉRICA DO SUL. II Congresso Internacional IGLU. Florianópolis, dez, 2011. 
MEYER JR, Victor. A prática da administração universitária: contribuições para a teoria.Universidade em Debate, jan-dez2014.

NUNES, Simone Costa. O discurso e a prática da formação baseada em competências: um estudo em cursos de graduação em Administração. Administração: Ensino e Pesquisa, v. 11, n. 3, p. 395-424, 2010.

PEREIRA, Cleber Augusto; ARAUJO, Joaquim Filipe Ferraz Esteves; DE LOURDES MACHADO-TAYLOR, Maria. The Brazilian higher education evaluation model: "SINAES" sui generis?. International Journal of Educational Development, v. 61, p. 5-15, 2018.

POTGIETER, Ingrid. BASSON, Johan. COETZEE, Melinde. Management Competencies for the development of heads of department in the higher education contexto: a literature overview. South African Journal of Labour Relations, v. 35, n. 1, 2011.

KOK, Seng Kiat; MCDONALD, Claire. Underpinning excellence in higher education - an investigation into the leadership, governance and management behaviours of high-performing academic departments.Studies in Higher Education, 42:2, 210-231,

2017. DOI: $\underline{10.1080 / 03075079.2015 .1036849}$

RECKWITZ, A. Toward a theory of social practices: a development in culturalist theorizing. European Journal of Social Theory. n.5, v. 2, p. 243-263, London: Sage, 2002.

REIS, Fábio. Destruição Criativa no Ensino Superior: O rompimento de modelos convencionais de ver e presentar uma fase de transição, que privilegie a inovação. Log da Fnesp com Fábio Reis. Jun., 2016. Disponível em: $<\underline{\text { http://fnesp.com.br/blog/destruicao- }}$ criativa-no-ensino-superior/>. Acesso m 26/11/2016.

RUAS, Roberto. Gestão das competências gerenciais e a aprendizagem nas organizações. Artigo EA/PPGA/UFRGS, 2002.

SAMPAIO, Helena. Ensino superior no Brasil - o setor privado. São Paulo:

Fapesp/Hucitec, 2000.

SCHATZKI, T. R. Introduction - Practice Theory. In: SCHATZKI, T. R.; KNORR CETINA, K.; VON SAVIGNY, E. (eds) The Practice Turn in Contemporary Theory. London and New York: Routledge, 2001.

SVEIBY, K. E. The Knowledge Company: Strategy Formulation in Knowledge-Intensive Industries. Int. Review of Strategic Management. Vol. 3 D. E. Hussey ed. John Wileyand Sons Ltd, 1992

VERGARA, Sylvia Constant. Projetos e Relatórios de Pesquisa em Administração. São Paulo. Editora Atlas, 2014.

VIEIRA, Ricardo S. G. FONSÊCA, Francisco R. B. O Sensemaking como Ferramenta Estratégica para o Desenvolvimento de Redes de Relacionamentos de Negócios no Contexto das Empresas de Base Tecnológica. In: IV ENCONTRO DE ESTUDO EM ESTRATÉGIA. ANPAD. Recife, jun., 2009. 
WATERMAN, R. Jr, Adhocracy: The Power to Change, Whittle Direct Books, Memphis. 1990.

WEICK, Karl. Educational organizations as loosely coupled systems. Administrative Science Quarterly, 21 (1976), 1-9 (part).

Sensemaking in organizations. Thousand Oaks: Sage Publications.

1995.

YANG, R. Globalisation and higher education development: a critical analysis.

International Review of Education, 493-4: 269-291. The Netherlands: Kluwer, 2003.

ZANETIN, Roseli. Poder, cultura e instituições de ensino superior particulares (IES): desempenho e comunicação. Tese de doutorado apresentada ao Programa de Pós-graduação em Comunicação, Universidade de São Paulo (USP), São Paulo, 2006.

ZAMBERLAN, Carlos Otávio. CERETTA, Paulo Sérgio. GHILARDI, Wanderlei José. MINELLO, Ítalo Fernando. Orientação para competências na gestão de Instituições de Ensino Superior públicas e privadas: um estudo da região de Santa Maria - RS. In: III SEGeT - SIMPÓSIO DE EXCELÊNCIA EM GESTÃO E TECNOLOGIA. Rio Grande do Sul, 2010.

ZARIFIAN, Philippe. Objetivo Competência: Por Uma Nova Lógica. São Paulo: Editora Atlas, 2012. 